\title{
SCHREINEMAKERS DIAGRAMS OF QUINARY SYSTEMS WITH K+2 PHASES: A SYSTEMATIC CLASSIFICATION KONSTANTIN MARIOLACOS ${ }^{1}$
}

\section{ABSTRACT}

In the present study, a systematic classification of the Schreinemakers diagrams for quinary systems with $\mathrm{K}+2$ phases is undertaken. The indifferent phases of the respective systems are also considered. In doing so, the same characterization already applied in the Schreinemakers diagrams of quaternary systems is used. In addition, as an application of the above classification, the theoretical treatement of the system KMASH is undertaken.

KEY WORDS: Schreinemakers diagrams, quinary Systems, K+2 phases

\section{CLASSIFICATION AND CHARACTERIZATION}

In his pioneering work on P-T-diagrams, which also carry his name, Schreinemakers (1915-25) considered only the general cases of the quinary systems. In this way he found a total of eight different cases following his principle of the odd number of the bundles of the monovariant reactions in the respective system. As he has not made any systematical classification of the so called indifferent phases, it is the primary intention of the present study to do so. The same art of the classification that Mariolacos (1998) introduced for the quaternary systems is hereby applied. It is based on the following principle: one begins with the bivariant field of highest metastability and moves around the invariant point along the quickest path in the direction of the bivariant field with the same or secondhighest metastability until one is again at the starting point. In doing so, every bivariant field is labelled with its number of metastabilities written in square brackets. Furthermore an index, which indicates the class of the system - for the quinary systems: 5 - completes the notation. In this way it results to a combination of numbers, like the Miller indices in the Crystallography, which are characteristic for the system under consideration. The resulting "type" is significant for the respective system when its phases occupy arbitrary places in the space and, in this case, the sum of its indices is equal to the number of the coexisting phases at the invariant point, which for the quinary systems is 7 . This number is reduced with increasing number of indifferent phases in the respective system.

\section{RESULTS}

Beginning with the eight general cases of Schreinemakers $(1915, \mathrm{~V})$, labelled after the forementioned principle, successive indifferent phases were added and the systems ordered with decreasing sum of their indices; only systems with a sum of at least five (5) in their indices were considered. In this way, 43 different cases result which are shown in figures a to $\mathrm{h}$ in the original notation of Schreinemakers.

Figures a-h: Systematical classification of the Schreinemakers diagrams of quinary systems with $K+2$ phases
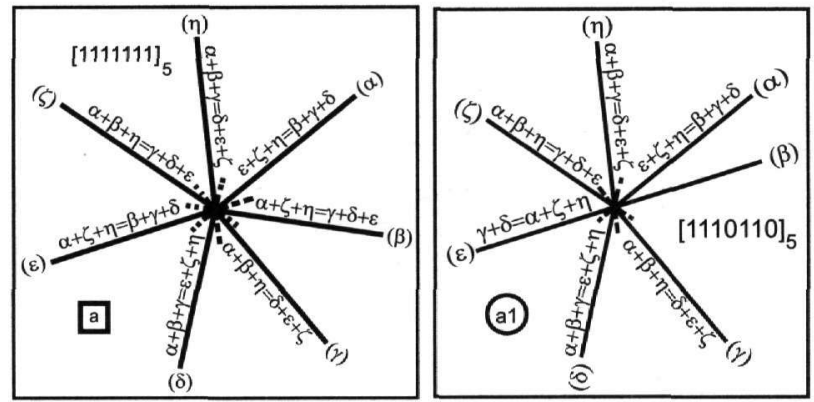

1. Mineralogisch-Kristallographisches Institut, Georg-August Universitot, Goldschmidtstr. 1, D-37077 Goettingen, Germany 

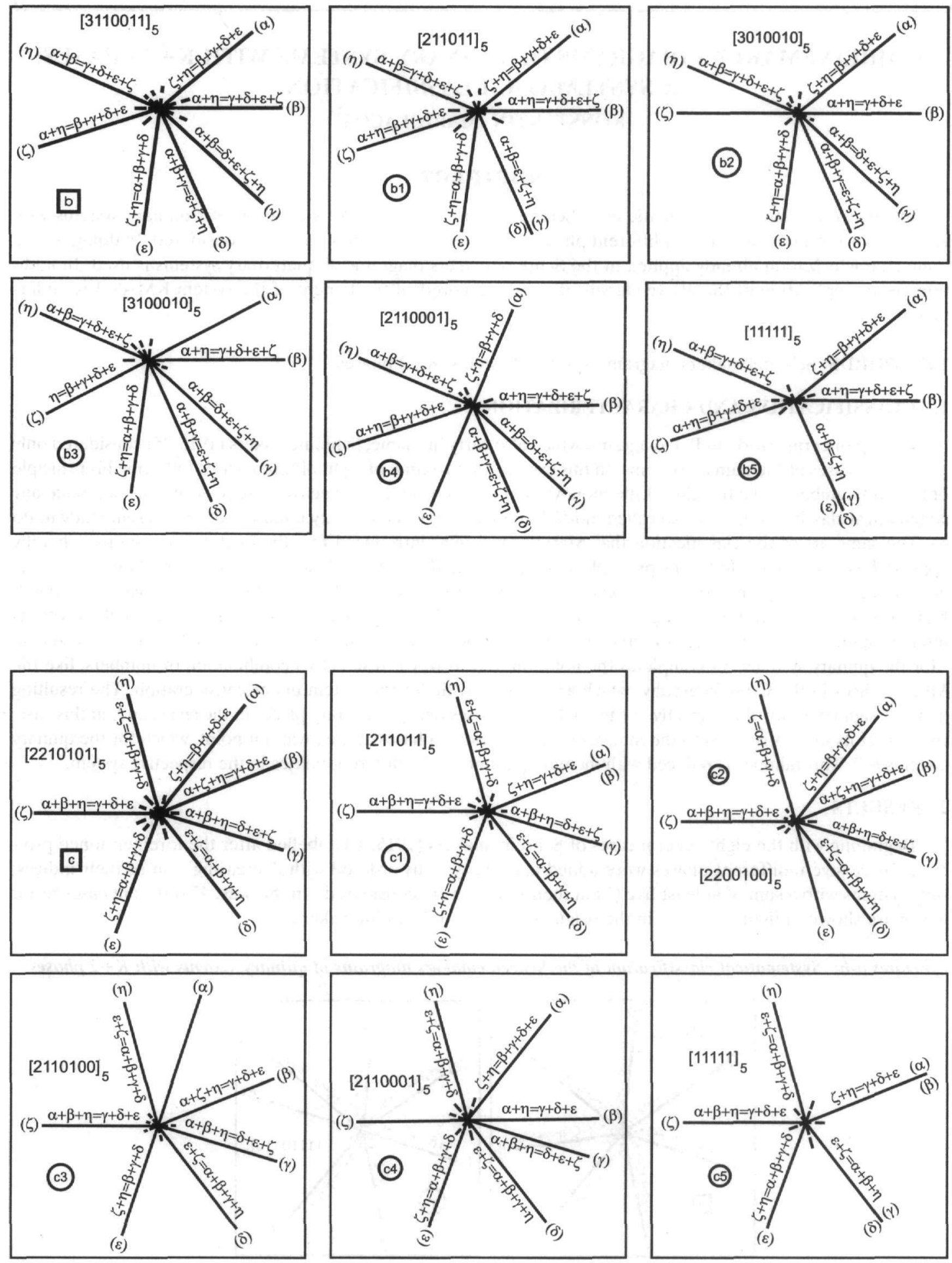

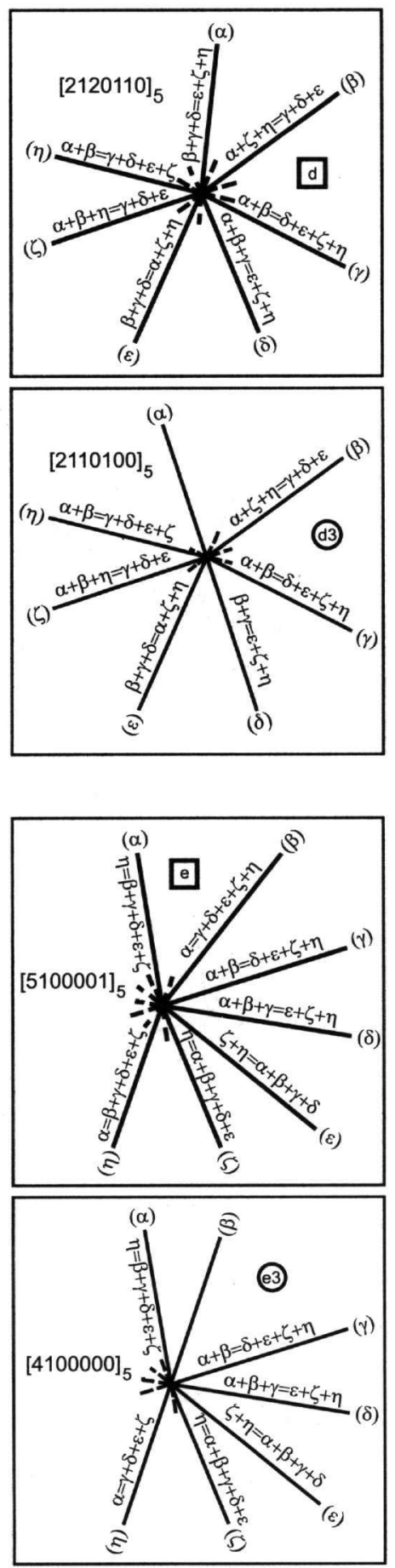
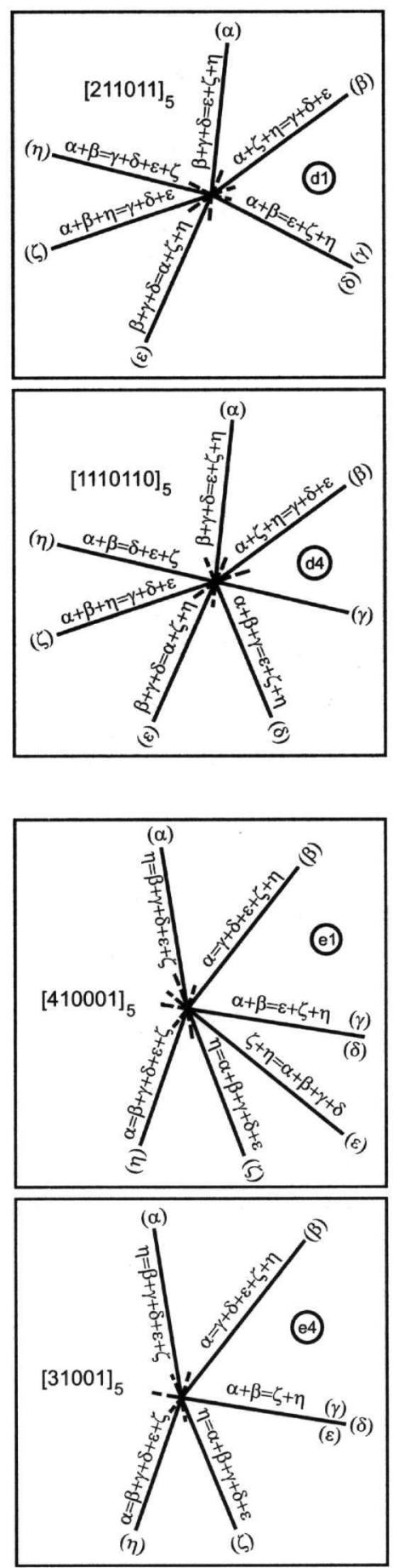
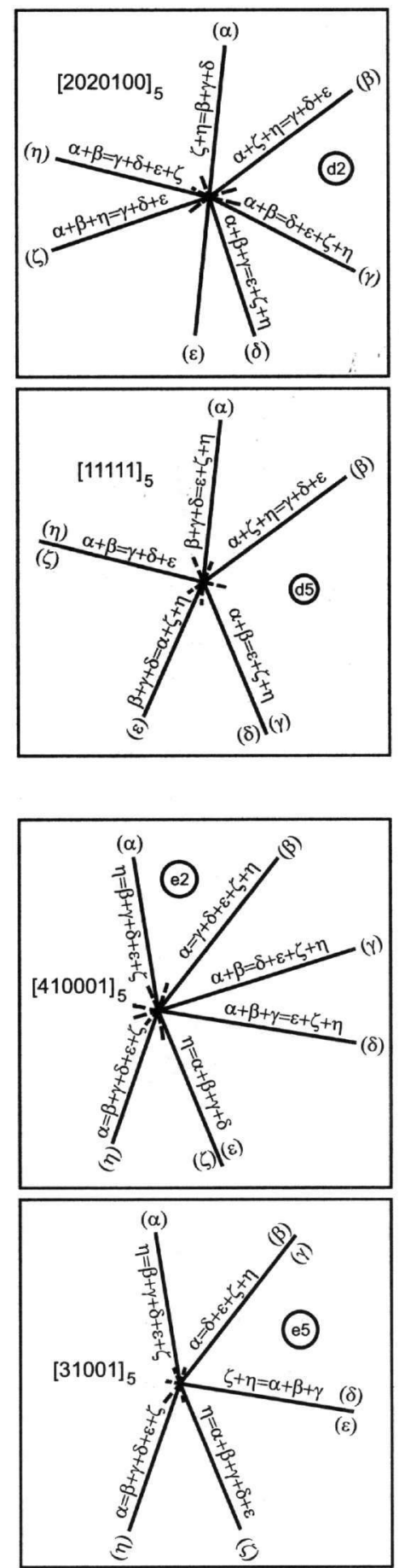

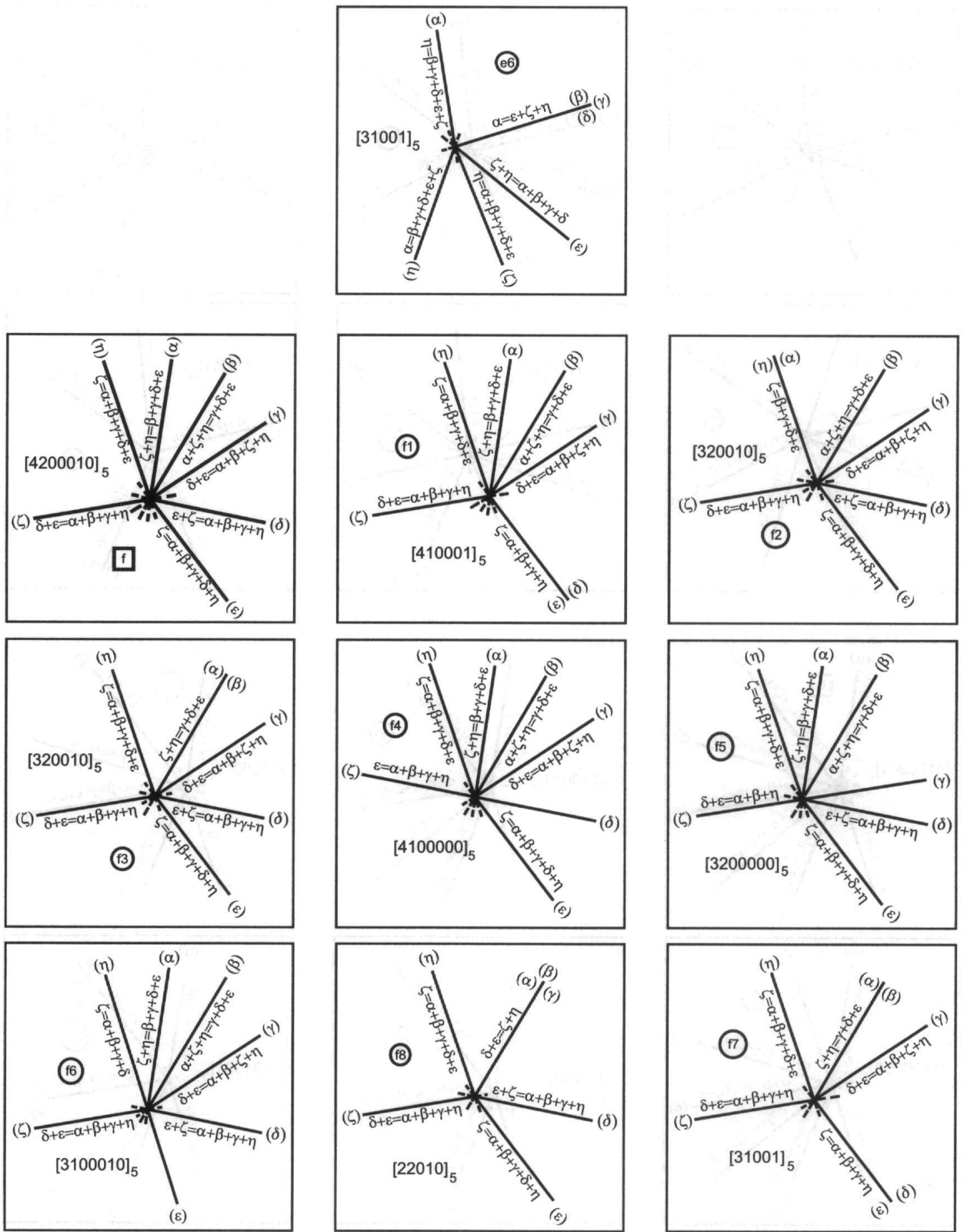

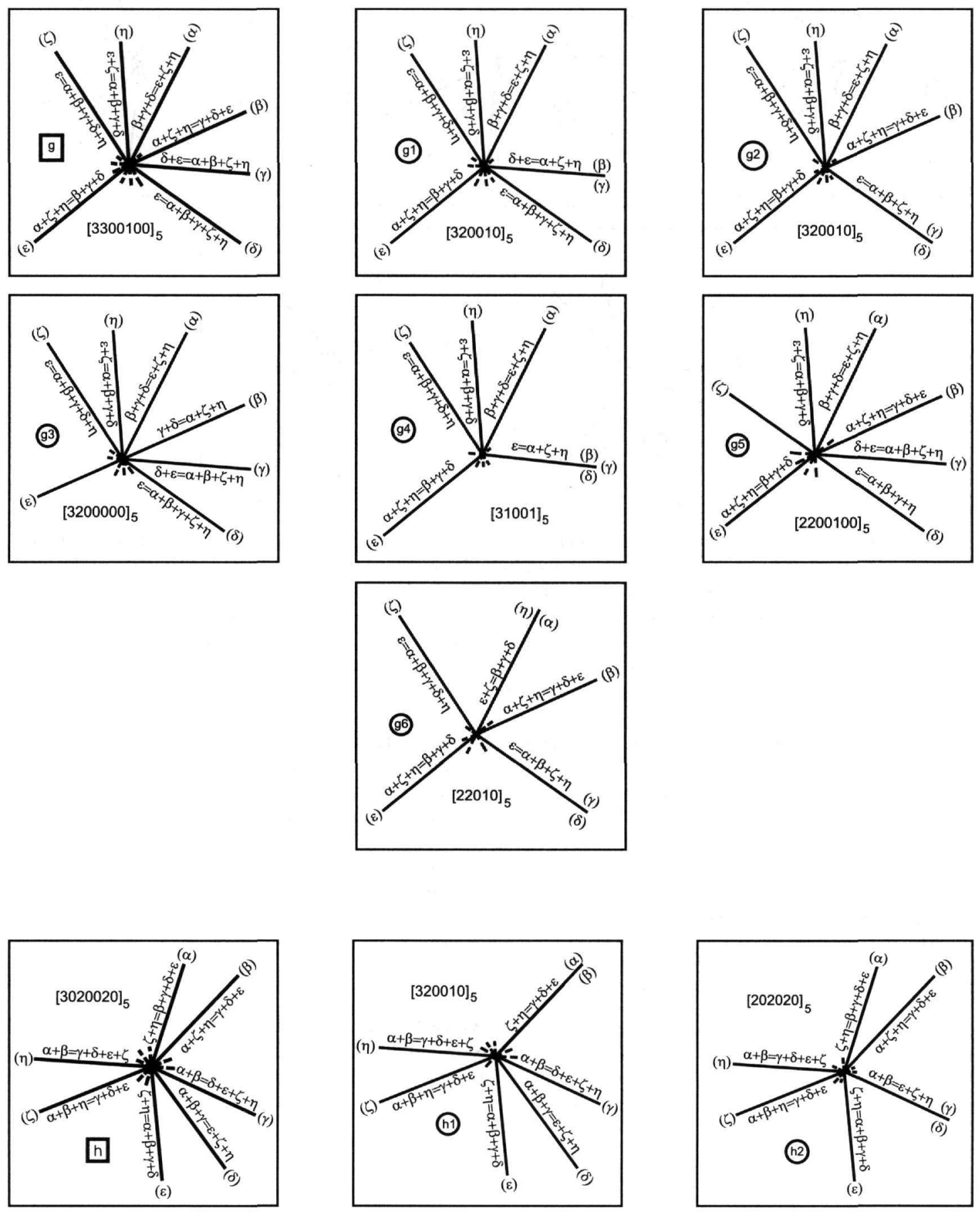

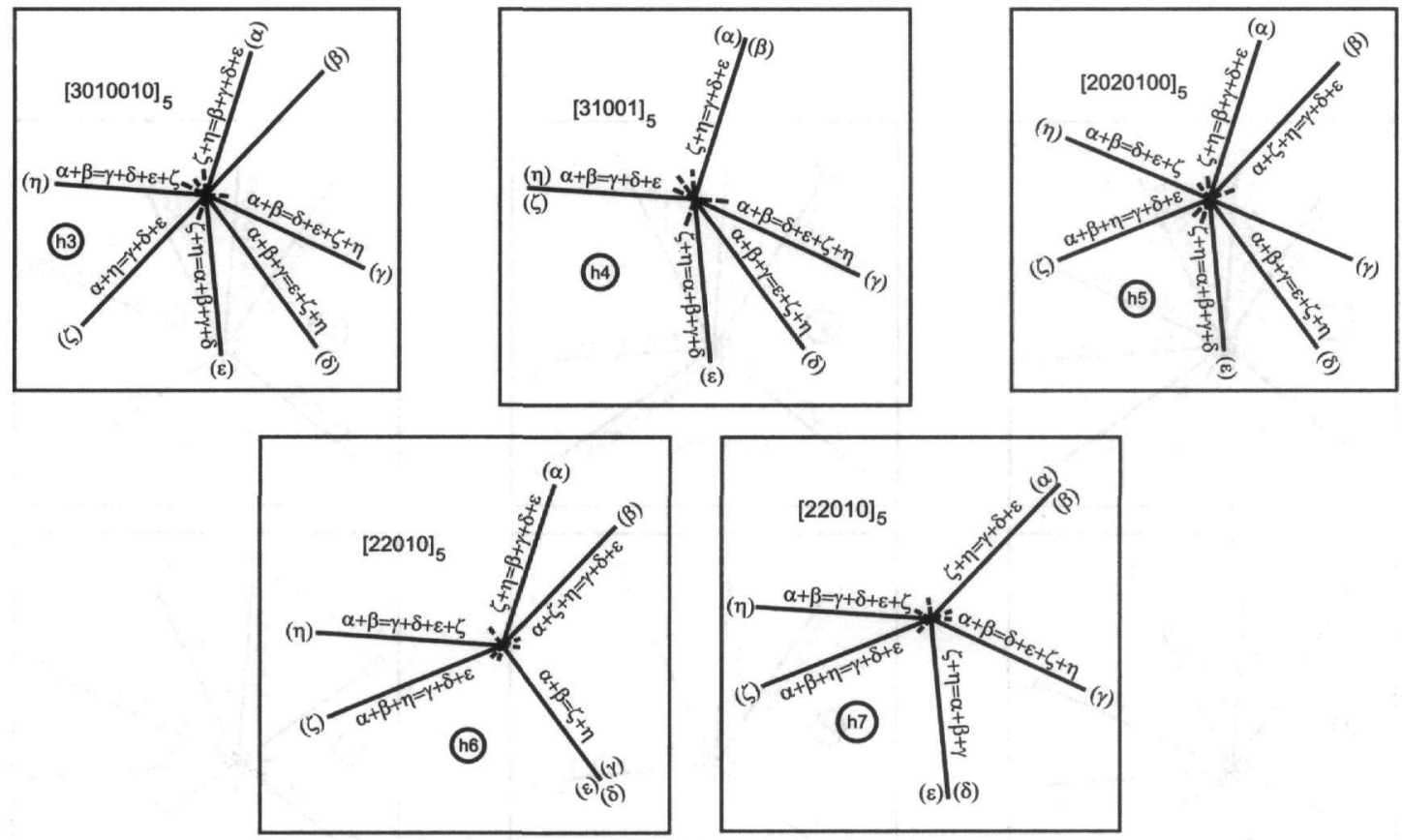

As it is obvious from the above figures, there are only two systems with significant indices: $[3010010]_{5}$ and $[202020]_{5}$; in all other cases the indices are common to at least two systems. The indices $[31001]_{5}$ are the most frequent as they are found in six systems. Nevertheless, if one takes in account the kind of the reactions which take place along the monovariant curves, one can find out that in the same class of systems these reactions are different to each other, eg. in the systems e4, e5, and e6, the the monovariant reactions are as follows:

Case e4:

$1 \longrightarrow 54 \mathrm{x} ; 2 \longrightarrow 21 \mathrm{x}$

Case e5:

$1 \longrightarrow 41 \mathrm{x} ; 1$

$1 \longrightarrow 53 \mathrm{x} ; 2 \longrightarrow 31 \mathrm{x}$

Case e6: $1 \longrightarrow 3$ 1x;

$1 \longrightarrow 53 \mathrm{x}$

$2 \longrightarrow 41 \mathrm{x}$.

The systems with the indices $[1110110]_{5}(\mathbf{a 1}, \mathbf{d 4}),[2020100]_{5}(\mathbf{d} 2, \mathbf{h 5}),[2110100]_{5}(\mathbf{c 3}, \mathbf{d 3})$, and $[3100010]_{5}$ (b3, f6) have indeed the same constellation of reactions along the monovariant curves, but nevertheless the respective systems belong to different groups of the Schreinemakers diagrams. The constellation of reactions with the indices [320010], which is common to five systems differs from each other and are as follows:

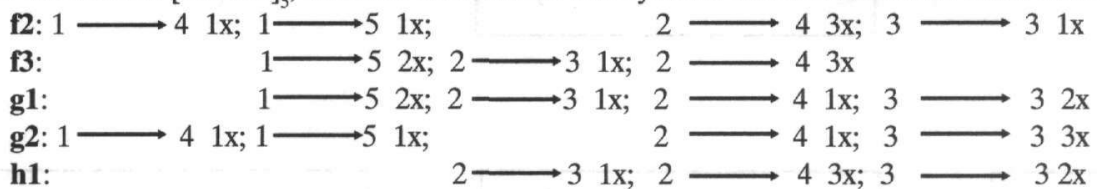

\section{MINERALOGICAL APPLICATION}

As a study case the system $\mathrm{K}_{2} \mathrm{O}-\mathrm{MgO}-\mathrm{Al}_{2} \mathrm{O}_{3}-\mathrm{SiO}_{2}-\mathrm{H}_{2} \mathrm{O}$ (KMASH) is theoretically treated. The considered phases of the system are as follows: $\mathrm{K}_{2} \mathrm{O}$ Potassium Oxide; $\mathrm{MgO}$ Periclase; $\mathrm{Al}_{2} \mathrm{O}_{3}$ Corundum $(\mathbf{K}) ; \mathrm{SiO}_{2}$ Quartz; $\mathrm{H}_{2} \mathrm{O}$ Water; $\mathrm{K}_{2} \mathrm{MgAl}_{4} \mathrm{Si}_{7} \mathrm{O}_{20}(\mathrm{OH})_{4}$ PhEngite; $\mathrm{KMg}_{3} \mathrm{AlSi}_{3} \mathrm{O}_{10}(\mathrm{OH})_{2}$ PhLogopite. 
Table 1. The calculated entropy and volume changes and the P-T slopes of the reactions in the system $\mathrm{K}_{2} \mathrm{O}-\mathrm{MgO}$ $\mathrm{Al}_{2} \mathrm{O}_{3}-\mathrm{SiO}_{2}-\mathrm{H}_{2} \mathrm{O}(\mathrm{KMASH})$

\begin{tabular}{|c|c|c|c|}
\hline Monovariant Reactions & $\begin{array}{c}\Delta S \\
{[d J / \text { mol.grd] }}\end{array}$ & $\underset{\left[\mathrm{cm}^{3} / \mathbf{m o l}\right]}{\Delta V}$ & $\begin{array}{l}\text { dP/dT } \\
\text { [bar/grd] }\end{array}$ \\
\hline$E=O+P+2 K+7 Q+2 W$ & 3677.4 & 23.8 & 154.5 \\
\hline $2 L=O+6 P+K+6 Q+2 W$ & 560.4 & 5.8 & 96.6 \\
\hline $\mathbf{E}+\mathbf{5 P}=\mathbf{K}+\mathbf{Q}+\mathbf{2 L}$ & 3117.0 & 18.0 & 173.2 \\
\hline $4 L=E+O+11 P+5 Q+2 W$ & -2556.6 & -12.0 & 209.6 \\
\hline $6 E=5 O+11 K+36 Q+10 W+2 L(P)$ & 21504.0 & 137.0 & 157.0 \\
\hline $5 \mathrm{~K}+14 \mathrm{~L}=6 \mathrm{E}+\mathrm{O}+36 \mathrm{P}+2 \mathrm{~W}$ & -18141.2 & -102.2 & 177.5 \\
\hline
\end{tabular}

The reactions involved in the system together with the entropy and volume changes and the P-T slopes are given in Table 1. The data are taken from Robie, Hemingway and Fisher (1979) and those for phengite from Woods and Garrels (1987), while its density is estimated to $2.9 \mathrm{~g} / \mathrm{cm}^{3}$. The Schreinemakers diagram of the system has the type [410001] $]_{5}$ (case e1) and is given in Fig. 1.

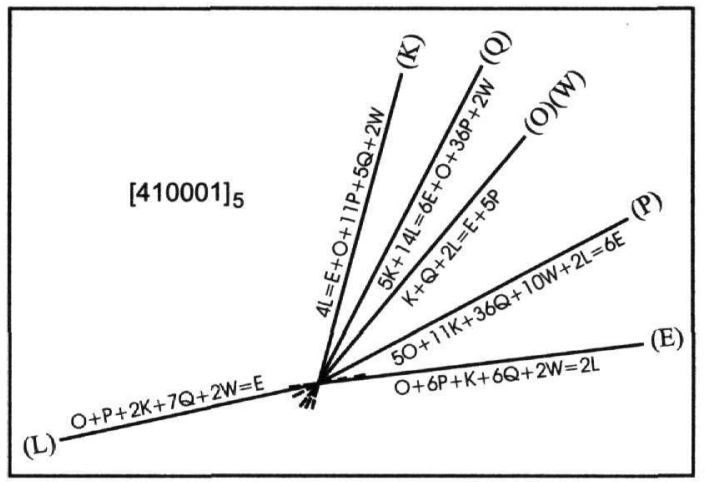

Figure 1: The Schreinemakers diagram of the system KMASH has the type [410001]

\section{ACKNOWLEDGEMENT}

I am indebted to my colleague Colin Lobban for the translation in English.

\section{REFERENCES}

MARIOLACOS K. (1998): Klassifizierung und topologische Systematik der Schreinemakers Diagramme für quaternäre Systeme mit K+2 Phasen. Bulletin of the Geological Society of Greece vol. XXXII/3, 49-58.

ROBIE R. A., HEMINGWAY B. S., AND FISHER J. R. (1979): Thermodynamic properties of Minerals and related Substances at $298.15 \mathrm{~K}$ and 1 bar Pressure and at higher Temperatures.

SCHREINEMAKERS F. A. H. (1915-25): In-, Mono-, and Di-Variant Equilibria. A Series of 29 Papers appearing in the Proceedings of Koninklijke Akademie van Watenschappen Te Amsterdam, I-XIII.

WOODS T. L., GARRELS R. M. (1987): Thermodynamic Values at low Temperature for Natural Inorganic Materials: An Uncritical Summary 